Article

\title{
Engineering eHeritage-A New Approach for Study of Intangible Cultural Heritage. Case Study: The Analysis of the Noise Produced by the Dacian Dracon
}

\author{
Silviu Butnariu ${ }^{(D)}$ \\ Department of Automotive and Transport Engineering, Faculty of Mechanical Engineering, Transilvania \\ University of Brasov, 29 Eroilor Blvd, RO-500036 Brasov, Romania; butnariu@unitbv.ro; Tel.: +40-268-418-967 \\ Received: 24 March 2019; Accepted: 9 April 2019; Published: 12 April 2019

\begin{abstract}
Preserving the past is an important task of the current generation because of the rapid changes that influence our society. There are certain objects or traditions that make us feel as though we are part of something and-a country, a way of life. The term 'cultural heritage' has seen many changes over the last decades and can be evaluated from a tangible or intangible point of view. Since the beginning of the 21st century, the recognition and protection of intangible cultural heritage (ICH) has seen an increased importance. ICH includes goods that can express the idiosyncrasy of certain groups, represent a specific skill, or tradition. This paper presents a working methodology on a structured approach to ICH elements, as well as a case study of such an object. At the same time, this paper proposes a new method of artifacts research, an approach that brings, in addition to engineering, expertise from several fields: Mechanics, construction, material resistance, flow of fluids, heat transfer, ICT, and virtual reality.
\end{abstract}

Keywords: Engineering eHeritage; intangible cultural heritage; Dacian Dracon; acoustics

\section{Introduction}

According to the Collins dictionary, the main meanings of the notion of heritage are (i) the evidence of the past, such as historical sites, buildings, and the unspoilt natural environment, considered collectively as the inheritance of present-day society or (ii) anything that has been transmitted from the past or handed down by tradition [1].

UNESCO has defined the notions of tangible cultural heritage and the intangible cultural heritage. Thus, according to Reference [2], cultural heritage is the legacy of physical artifacts and intangible attributes of a group or society that are inherited from past generations, maintained in the present, and bestowed for the benefit of future generations. This concept includes buildings and historic places, monuments, artifacts, etc., which are considered worthy of preservation for the future.

The concept of intangible cultural heritage means the practices, representations, expressions, knowledge, skills-as well as the instruments, objects, artifacts, and cultural spaces associated therewith - that communities, groups, and, in some cases, individuals recognize as part of their cultural heritage [3].

There are serious concerns about the recovery and protection of intangible cultural heritage. Some researchers have thoroughly studied the methods of conservation of the heritage that have been preserved to ensure sustainability for future generations [4], while others have even studied intellectual property protection in intangible cultural heritage (ICH) (copyright protection for $\mathrm{ICH}$, improved trademark protection and ICH geographic protection, patent protection for $\mathrm{ICH}$ ) due to the complexity of this concept and the difficulty of reconciling the various interests involved [5]. 
In the current sense, when we talk about preserving cultural heritage, we mean the following: Tangible things (unmovable heritage: Sites, monuments, artifacts, or underwater sites; and movable heritage: Museum artifacts) or intangible things: Stories, performances, dance, music, language, and knowledge.

On the other hand, there are things that do not fit exactly in any of the tangible or intangible categories, with access to some historical evidence that confirms their existence at a certain time, but which have not been discovered in the form of artifacts. In this category, we can give the example of Dacian Dracon flag, for which there is sufficient historical evidence of its use in the Dacian army and later in the Roman army (legends, references of historians, bas reliefs, coins) but which was not found under the form of artifact, and there is no sample preserved in our day. These types of objects fall into the category of tangible cultural heritage but must be studied under the procedure developed for the items of the intangible cultural heritage category.

Technological advances have led to important methodological changes in the preservation, protection, and recognition of cultural heritage [6]. A report from the European Commission [7] specifies virtual reality (VR) will offer "an impressive, immersive, interactive and involving product" and will also create an environment similar to reality. As such, VR is seen as an important tool that can be used for archaeological reconstruction and plays an important role in preserving cultural heritage [8].

The recently introduced concept eHeritage, aims to create digital models in order to expose it in museums, being very different from the classical artifacts that are just expose. It aims to develop digital models as close as possible to reality. For that, it is necessary to carry out studies with human subjects in order to optimize them. Lately, most of the research work in this area, the recovery and reconditioning of cultural heritage, focused on the 3D digital reconstruction of historical sites, buildings, or artifacts with a visual role (statues, bas reliefs). These reconstructions are 3D geometric models only, without information on material properties, masses, densities, roughness, functions, and modes of operation.

In order to develop the concept of eHeritage with new characteristics of the digital model (such as simulating the functionality), we approach the new concept—Engineering eHeritage-so we can take a step forward and ask ourselves the following questions:

1. Is 3D geometry of the objects sufficient to achieve the concept of eHeritage?

2. What kind of elements should be added to this approach in order to extend the information on it?

3. How can we add the mass, structure, and equilibrium of elements in the virtual environment?

Can VRML (virtual reality modeling language) applications answer these questions? Can we extend the capabilities of VRML application software?

4. What can be done with this new information to the geometric model? Can it demonstrate the functionality of the reconstructed objects and their characteristics?

In this paper, I will try to demonstrate that the development of adding new features of the digital model containing only the $3 \mathrm{D}$ geometry is a positive thing that bring value.

\section{Materials and Methods}

\subsection{Hierarchy of the Activities in eHeritage}

Analysis has been carried out to determine a hierarchy of domains within the eHeritage concept. Thus, a method dedicated to these activities, CTQ analytic hierarchy process (AHP) prioritization, was used. The analytic hierarchy process (AHP) is a structured technique for organizing and analyzing complex decisions, based on mathematics and psychology. CTQs are the internal critical quality parameters that relate to the wants and needs of the customer. They are not the same as CTCs (critical to customer), and the two are often confused.

More people are involved in this test. They were first asked to identify new areas of development within the eHeritage concept, then to say their choice about the importance of a domain compared to 
others. Thus, with Qualica software, a hierarchy of these directions for the development of the new concept has been created (Figure 1). New research domains have been identified and hierarchized. The hierarchy obtained is the following: 3D reconstruction (exterior and interior), functioning of the artifacts, languages, clothes, visual sensation of material, knowledge, sounds, dance choreography, tells, legends.

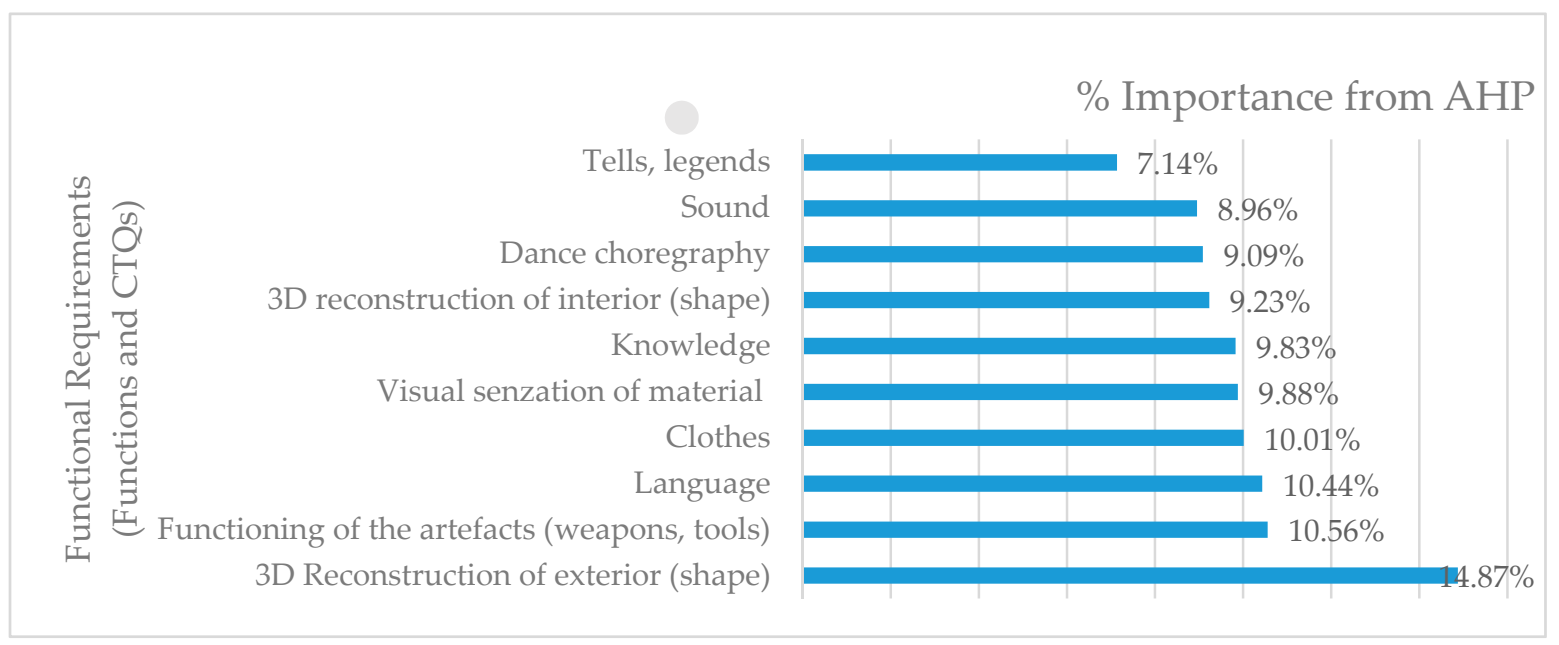

Figure 1. Analytic hierarchy process (AHP) analysis results.

Running this analysis, we can see that there are several areas of interest in using ICT in cultural heritage as well as their importance according to the preferences of a sample of specialists. We realize that the activities hierarchized by this method are not just the 3D reconstruction of buildings, but this list shows new activities not taken into account in eHeritage research recently [9]. As a result of the above, in this paper, we will focus on other research directions and less on the classic one of the reconstructions of the archaeological buildings and sites.

\subsection{Proposed Algorithm}

The following algorithm has been established to analyze artifacts using ICT methods (Figure 2).

1. Identifying of the system/piece/artifact to be analyzed, and the motivation of the analysis. Comparison between the concepts of Heritage and eHeritage for tangible objects (reference will be made to all aspects of defining heritage: Materials, shape, textures, functioning).

2. Inventory and classification of archaeological evidence and available information. All historical sources are to be considered: Parts of artifacts, inscriptions, legends, traditions, and connections with other elements, to be able to outline the profile of the studied element.

3. Establish the 3D reconstruction method and creating the 3D model.

4. Identification of the functionality of the artifact and the characteristics to be analyzed (mechanical resistance, mode of operation, technical characteristics, flow of fluids, produced noises, e.g., Dacian flag, musical objects, manufacturing technologies, (e.g., bell casting)). Establishing the analysis method (finite element method, FEM; multibody, MB; fluent, and creating mathematical model). This is a new approach, transforming the simple 3D surfaces in objects with own properties by extending the concept of virtual reconstruction by adding information on the composition and structure of rebuilt element, including physical and mechanical properties.

5. Creating the model for analysis (e.g., materials and shapes-FEM, functional mechanism-ADAMS, Matlab blocks)

6. Running the digital model and extracting data. Types of results obtained. Analysis of results and conclusions. 


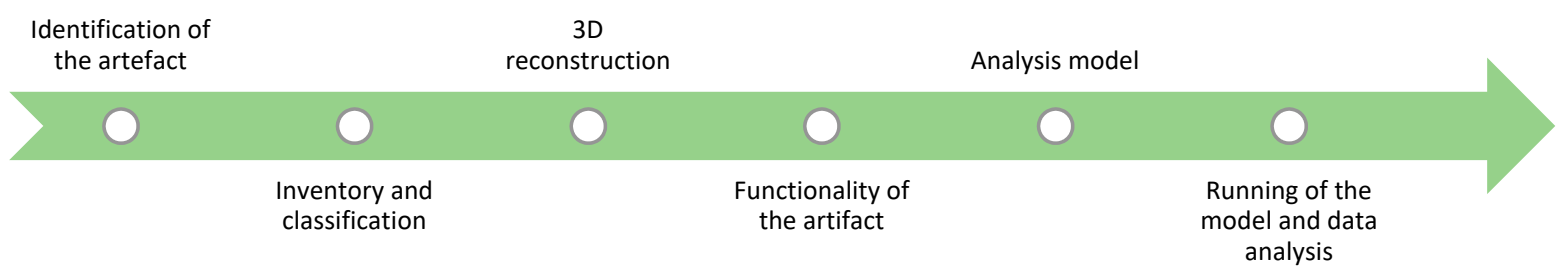

Figure 2. The proposed algorithm.

\subsection{Examples of Engineering eHeritage}

\subsubsection{Author's Research}

Below are some examples of projects and works made by the author that highlight the issues that are being pursued. In some, only 3D reconstructions and visualization are presented through various methods: On display, in the cave, with virtual reality (glasses, phone, refract pyramid) or augmented reality, and in others, new methods of analysis will be presented.

Reference [10] proposed a haptic device that studies the cutting of logs with a manual saw, one of the most important activities for people living in the mountains. Lately, this profession is only practiced traditionally, being largely replaced by automated processes. The proposed structure for the haptic device has the main characteristic of disengaging the two types of force present in the cutting process: Pulling the saw and pushing down. The latter influences the depth of teeth cutting, and also the strength of the stroke. The proposed haptic device also allows two-way movement: Forward and back for cutting and down to indicate the progress of the cut. The haptic simulator and interface to experiment with the woodworking process with a saw needs a virtual environment, a haptic device, visual and acoustic feedback, and control laws to generate feedback. When a single person uses this interface, an avatar replaces the partner.

In Reference [11], the authors want to improve the human abilities in order to understand how the ancient bow works and the sensations it exerts on the human body. A functional haptic model has been developed and the study proposes an immersive VR simulator for recreating the experience of shooting with old bows. Initially, three types of real replica bows were tested on the dynamometer and the force-displacement diagrams were plotted. With these values, the electric motor from the haptic device was programmed in order to simulate different types of old bows. For testing with various users, a virtual environment with various targets was created that ran on VR glasses.

Another interesting artifact is an old printing press (16th century), located in the First Romanian School in Brasov, Romania. The piece is exposed in the museum and it is made of wood but cannot be used to demonstrate the functionality. That is why a functional 3D digital model was built into a mechanical design software (CATIA) and then finished using the VRML programming language [12]. This functional model, built as a mechanism, is easy to use in demonstrating the functioning of the printing press.

Reference [13] describes a method of 3D reconstruction of a missed building based on a single image obtained with a completely uncalibrated camera or even lithography. The method proposed in this paper involves a multimodal approach: Digital photogrammetry, 3D photo modeling, CAD design, parameterization, and VRML programming. For visualization, we used a 3D CAVE system. The rebuilt 3D model offers the possibility of viewing details, changing geometry, dimensions, texture, environment, and viewpoint, and can be accessed with Internet browsers and a VRML client plug-in. As an example and a practical application of the presented method, the 3D virtual reconstruction of the "St. Vineri" demolished church in Bucharest (Romania) was completed in Reference [13]. The sources of virtual reconstruction were historical archival, architectural, and contemporary information.

In References [14,15], we propose a methodology for 3D virtual reconstruction of objects that can be applied to virtual restoration. The presented method is based on augmented reality technologies, which allow the virtual restoration of the original patrimony object by co-locating the virtual 3D reconstructed real estate model. The proposed method consists of the following steps: Obtaining the 
documentation on the damaged heritage object, processing the documentation, 3D reconstruction of the monument, completing the details, and registering the 3D co-located virtual model. This method offers the possibility of better perception of the damaged object. The production of the proposed method is a reconstructed 3D model of the patrimony object, which can be co-located with the real object, using common equipment such as Smartphone or Tablet PC. The application of the proposed methodology, which is used as a case study, was carried out in Brasov (Romania), at the Black Church. The advantage of this 3D virtual reconstruction methodology is the use of inexpensive equipment, as only ordinary video and computerized devices are needed.

\subsubsection{Other Research Activities}

Lately, a new approach to cultural heritage has taken place. It is the question of the engineering analysis of the composition of the materials used in the construction of the buildings or artifacts, as well as new ways performed for their cleaning, reconstruction, and protection. For example, Roman cement, able to harden underwater, is well known for a multitude of civilian constructions in the Roman Empire [16,17].

In this area, there are concerns about the research of emulsions capable of cleaning and protecting marble surfaces or wooden parts. Thus, for marble or stone parts, substances based on nanotubes for the purification of artifacts [18] or nanocomposites capable of providing eco-sustained protection of cultural heritage objects in the external environment [19] are studied. In Reference [20], emphasis is oriented to the identification of halloysyte (aluminosilicate clay mineral) nanotubes capable of maximizing the efficiency of wood artifacts consolidation and long-term protection in the event of exposure to atmospheric conditions.

In other research papers, the topic of how to visualize ICH elements is addressed. Virtual reality with leap motion technologies can be used to virtually reconstruct hand movements of some characters in applications that target handicrafts [21]. In order to improve the features of scenes or landscapes, augmented reality [22] or virtual reality [23] technologies are used.

The digitization and visualization of traditional dances [24], languages used by various populations in the same geographical area [25], or ancient rituals [26] represent other research directions for the preservation of ICH elements. In References [27,28], they proposed the development and use of the i-Treasures web platform, through which knowledge exchange between researchers and the transfer of know-how from ICH bearers to apprentices can be made.

At the same time, some ICH components are reconstituted based on serious games or educational games where immersive techniques such as virtual environments and augmented reality have clear potential to support the cultural heritage experience of the general public $[29,30]$.

Another example would be the technique of archaeoacoustics, which represents a complex research subject that includes fields such as ethnomusicology, archaeology, engineering, acoustics, modeling, etc. As part of archaeoacoustics, acoustic heritage allows the assessment and recovery of cultural heritage, such as ancient buildings [6,31-33] or musical instruments $[34,35]$.

\subsubsection{Limitations of the Study}

In the analysis of digital models, other engineering methods of investigation can also be used. For example, to study the central heating methods of Roman baths (Hypocaust) based on the double floor, it is possible to use the finite element analysis technique CFD analysis [36]. In this example, research with traditional methods is very difficult to achieve [37]. The fabrication, movement, and mounting of the gigantic statues (Rapa Nui) of Easter Island is also a subject that can be approached through engineering-based simulation.

Therefore, I must note that there are many ways to analyze the ICH elements, but in this paper, the emphasis will be on only one study procedure-one that targets a number of elements for which there is no sample in museums, but there is sufficient historical information on their existence and 
operation. Many elements that fall into ICH cannot be analyzed using this procedure (traditions, songs, dances, rituals, legends, etc.), and a new study approach is needed.

\section{Case Study: Dacian Dracon}

\subsection{The First Step-Identify and Clarify the Problem}

The Dacian Draco has an interesting legend and appears in many historical sources. This element was the battle flag of the Dacians, Costobocs, and Tyragetes on the current territory of Moldova (northeast side of Romania) as well as of the Daco-Thracian Moesses from the south of the Danube river. The word Draco (Latin) and Dracon (Greek) mean "serpent" and "dragon". It has the body of a dragon or a serpent and the head of a wolf with its jaws open. While the wolf's head was made out of bronze or silver, the body was made of a textile material. The hollow wolf's head was mounted on a pole and the noises that were produced by the banner when the wind blew were unusual and terrifying. The use of such a banner played the role of scaring the enemy's horses and discouraging their troops [38].

The reason the Dacians chose a wolf as their totem has a rich ethnographic and folkloric background. All wild animals, regardless of their size or ruthlessness, can be tamed, except for the wolf, which prefers to die of hunger instead of giving up his freedom. The legend says that a tamed wolf saved Decebal's life from a pack of wild wolves. The Dacian king managed to survive only because of the sacrifice of his trusted companion, which died defending him.

In folk tradition and in historical evidence, the ability of this flag to produce loud noises and powerful vibrations that were able to frighten their enemies or their horses is talked about.

Current research focuses on identifying and studying this flag, so as to confirm or invalidate information about producing powerful noises.

\subsection{The Second Step - Inventory and Classification of Archaeological Evidence and Available Information}

In the following, some historical proof on the existence and use of the Dacian flag are presented.

Trajan's Column is one of the most important monuments of European antiquity and a source of great importance for the knowledge of Romanian national history. Built by the architect Apolodor of Damascus, on the orders of Emperor Trajan, the monument represents a wonderful visual chronic of the Dacian-Roman war. The Column was inaugurated on 12 May 113 AD and is still preserved in the Trajan's Forum in Rome.

The column has a height of about $30 \mathrm{~m}$ and is decorated with a spiral-shaped bas relief that depicts scenes from the Dacian-Roman confrontations. Originally, the column had on its top a statue of Trajan, which disappeared and was replaced in 1598 with a statue of St. Peter, made of bronze.

The bas reliefs show battle scenes from Trajan's campaigns against the Dacians 101-102 (at the top of the column) and 105-106 (at the bottom). An apogee of the art of the Roman historical bas relief, the 124 episodes that spiral the column and illustrate Trajan's comments on the Dacian wars (De bello dacico), preserve their cultural relevance by their historical documentary character.

In Roman antiquity, architectural monuments as well as sculptures (reliefs and statuettes) were painted, i.e., colored with vivid colors. This way of visual perception in Roman society was a possible "legacy" from Greek art using the same method to color its own architectural and artistic monuments. Today, in the Western world, such a vision of architecture and sculptural art is no longer accepted as such during Egyptian, Greek, and Roman civilizations, etc., as well as in the occult Western religious age [39].

Of the 2662 figures, Emperor Trajan appears in 58 of them. Of the total of 155 scenes, $29 \%$ are scenes from the march to Dacia; in $21 \%$, there are presented battle scenes, construction activities $12 \%$, negotiations $9 \%$, sacrifices $7 \%$, Trajan's speeches $6 \%$, and the rest are other events or data submitted by historians [40]. 
One of the most important elements for the Dacian army, presented on the Column in more than 20 scenes, is their flag in the form of a wolf head, called Dacian Draco.

Below, some historical information on the existence of these battle flags, their provenance, and their use is presented. The author did not find a historical source that made it clear that these flags were built to frighten their enemies or their horses, but the engineering study starts with this hypothesis, according to the fact that flags produced very strong noise when the air passed with the speed through them.

One of the most important historians of the Roman Empire, Arrianus, referred in his work to the dracones (Tact., 35.3-4). In Wheeler's translation and interpretation [41], the Roman army used these flags and it is said to be a hissing cloth. Presented here are some possibilities of the origin of this flag: Scythian, Sarmatian, Dacian, Parthian, and Thracian. Nevertheless, whatever the origin of this flag, it is very clear that there is irrefutable proof of its use by the Dacians (on Trajan's Column) and then, after the Dacian wars, this flag was taken over by the Romanian army [41].

In Reference [42], there is talk about the Roman cavalry that used these flags to recognize the groups on the battlefield. These flags, in the form of a canvas roller, stood vertically and, only in the run of the horse, swelled in the wind and slid horizontally so that they could be seen from afar.

Robert Vermaat's research (historian, founding member of re-enactment group Fectio, which explains the Roman army) shows that the dragon flag was originally just the cavalry sign. Its role was to determine the direction of the wind, to orient the arcs. The wolf's head was made of metal-plated wood, made up of two halves, the lower one being furniture (like the carol), and the snake tail made of stitch fabrics, fused by stitches. Through the open mouth of the wolf, the air enters and the tubular body swells, which produces both a snake's bruise and a mighty whistle. The flag-dragon carrier went to the forefront of the archers, carrying it in his left hand so that they could correct their shooting according to the dragon's movements, pointing to the direction of the wind [43].

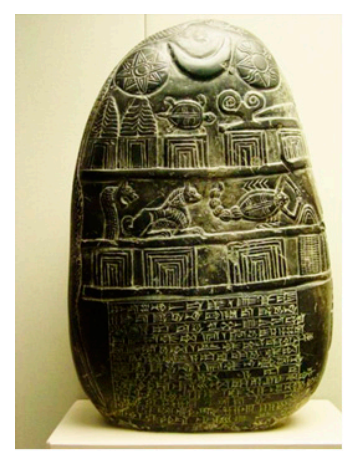

(a)

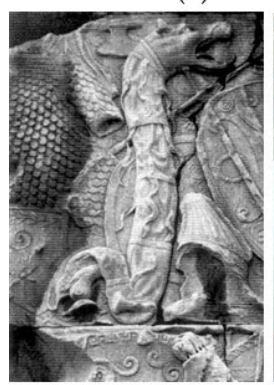

(d)

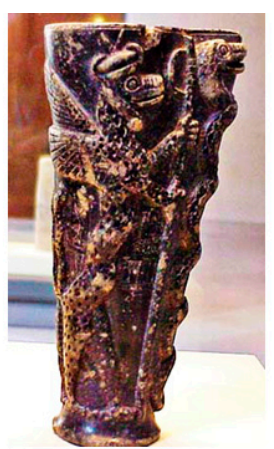

(b)

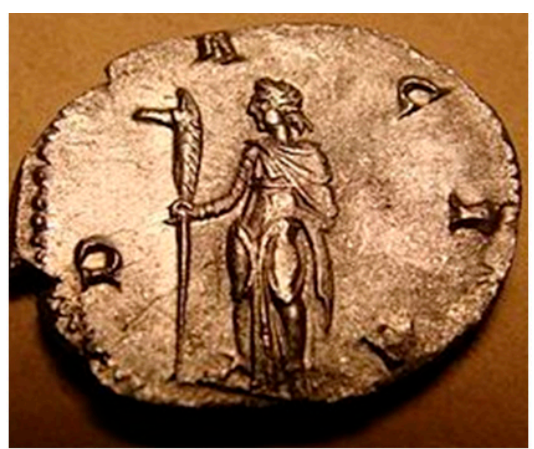

(c)

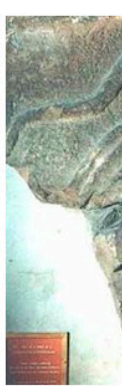

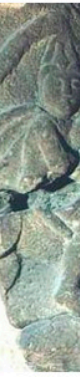

(e)

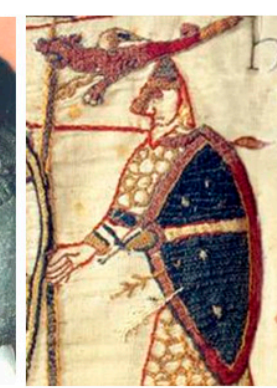

(f)

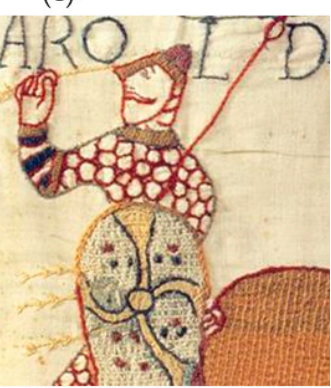

(f)

Figure 3. Archaeological findings: (a) The heavenly snake with a wolf head, as the emblem of the god Dumuzi temple, on a Sumerian tablet dating back to 2300 B.C.; (b) the wolf-headed snake began its history as the emblem of the Daos god, on a Sumerian seal; (c) the coin issued by Trajan, face (the effigy of the god Daos) and back (Dacia holds the dragon snake-flag); (d) the Dacian flag on the Trajan's Column; (e) later representations of the Dracon flag used by horseman wearing Sarmatian Lamell (aprox. 310 B.C.); (f) dracon flag on the Bayeux Tapestry, commemorating the Battle of Hastings [43,44]. 
Another stage in analyzing the Draco is gathering all the archaeological findings (Figure 3) such as written descriptions, pictures on ancient urns or columns, fragments from excavations, etc. In the Hallstatt Period, the symbol of a dragonhead or a serpent was quite common in ancient Dacia and could be found on silver Dacian bracelets and other similar ornaments.

A very important element is that archaeologists have not discovered any artifacts on the territory of the former Dacia province. This can be explained by the hypothesis of making the Dacian flags of the thin bronze sheet that have not resisted the oxidation process for 2000 years. However, on the territory of the former Roman Empire, in present-day Germany, a well-preserved dragon head made of copper has been found, which could be part of a battle flag (Figure 4). The difference and similarities between this dragon/snake head and the Dacian wolf must be observed.

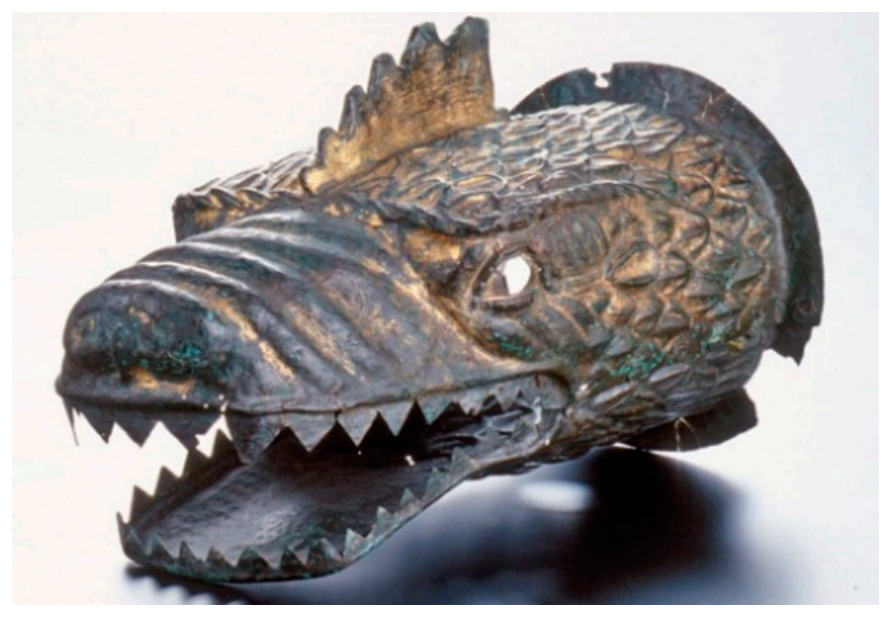

Figure 4. Die Drachenstandarte von Niederbieber [45].

On the other hand, there are some archeological evidences with another type of device-carnyx (Figure 5). The carnyx was a bronze trumpet used by Celts between c. 200 BC and c. AD 200, with an elongated $S$ shape. It seems that this trumpet was used in warfare, in order to intimidate opponents with the strong noise [46]. Based on archaeological evidence, the carnyx differs from the other two battle flags because it functions as a trumpet and does not emit noise by moving.

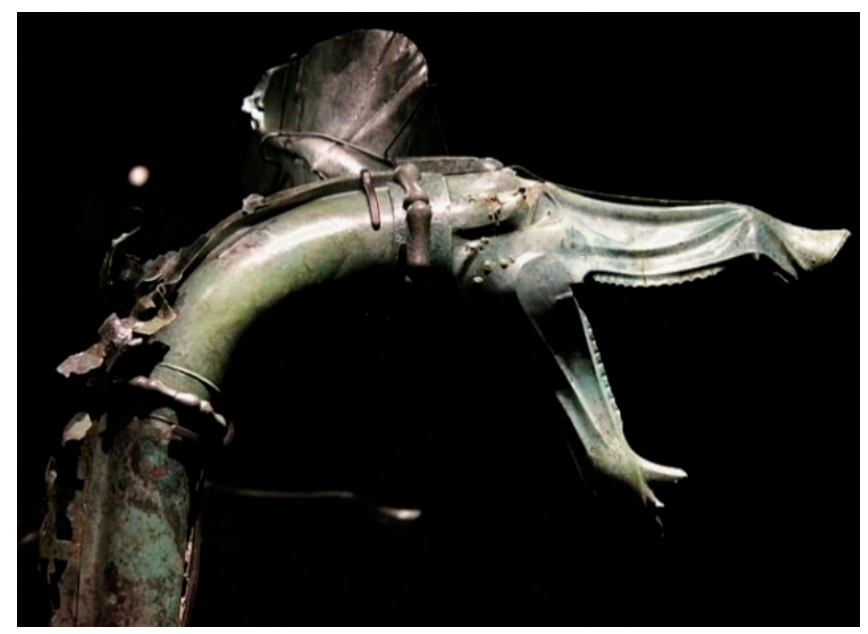

Figure 5. Carnyx from the recently discovered Tintignac group [46].

Taking into account many similar elements between the two war flags (Dacian Draco and German Dragon), which appear in very serious historical evidence, we can take the dimensions and manufacturing technology from the German dragon and transfer them to the Dacian flag. 
During the excavations near the castle Niederbieber, the famous "Equestrian Flag of Niederbieber" was discovered, the only original known of this type (see Figure 4). The dragon's head, made of thin copper sheets, has a length of $30 \mathrm{~cm}$, and rotates around a vertical axis. Initially, the head was seated on a vertical bar, and at the rear end had a tubular tail, imitating the dragon's body. When the rider raises the standard to a gallop, the wind slips through the open throat and causes a horizontal settlement [45].

In some historical evidence, the flag appears to be carried by riders on horses, and in another, by pedestrians. Here arises the question of the relative air speed to the flag. It can be seen that, in both cases, the flag is also represented in a horizontal position; that is, it is swollen by the wind.

According to the representations on the Trajan's Column, the Dacian flag always appears in most cases with the tail in a position close to vertical, worn only by pedestrians (Figure 6). This means that the body of the flag is unlikely to be swollen by the carrier's speed and, in the absence of a strong wind, the flag remains hanging.
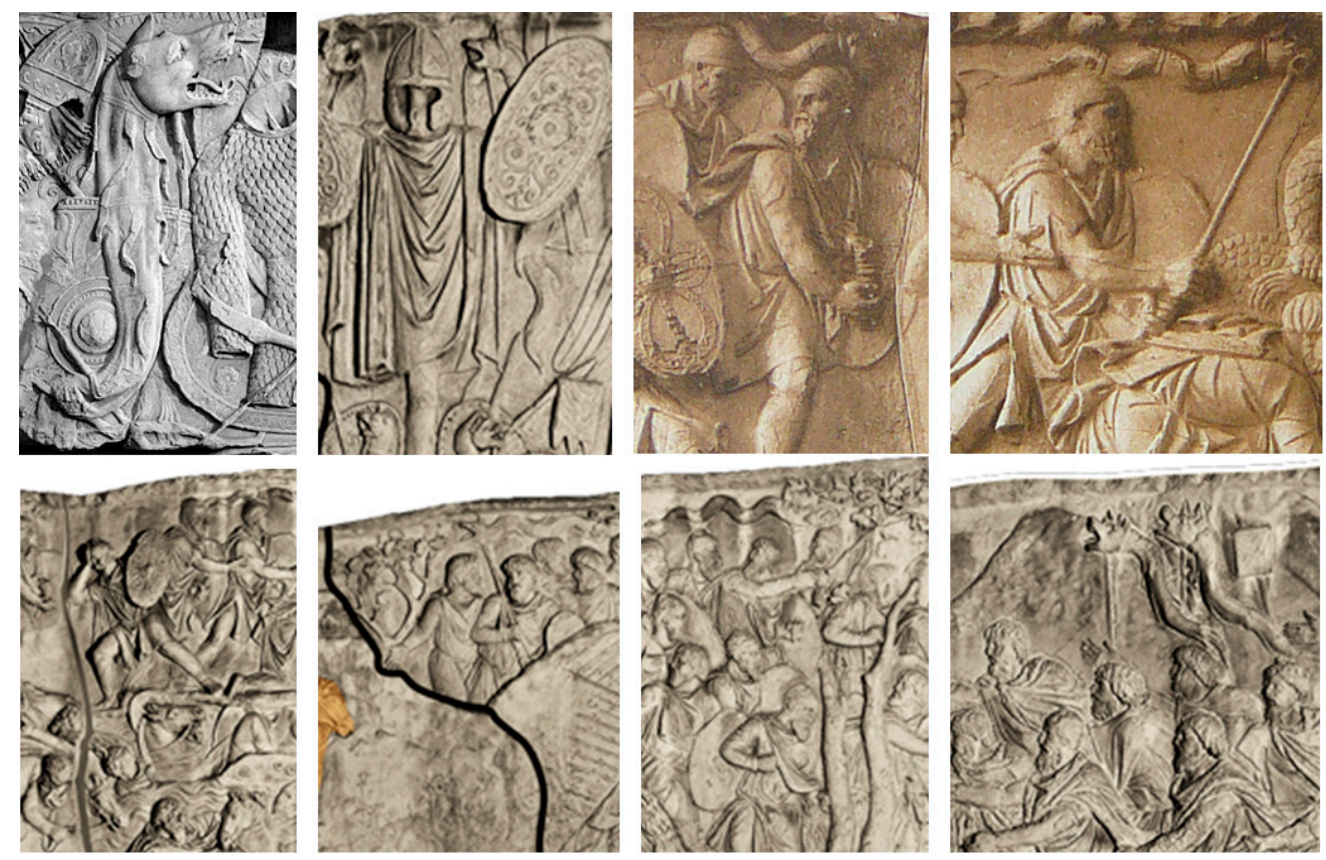

Figure 6. The Dacian flag represented on the Trajan's Column [40].

\subsection{Step Three-Establish the 3D Reconstruction Method and Create the 3D Model-Virtual Model for Analysis Using FEM}

The construction of the geometric model of the Dacian flag is based exclusively on the information provided by the bas reliefs of the Trajan's Column $[39,40]$. There are models rebuilt by various people, in some associations for the reconstruction of the armed struggles between the Dacians and the Romans. These replies are made on the basis of the same historical evidence as we have. All rebuilt models are executed identically from the structural point of view: A rigid wolf head, usually made of metal sheets, and a snake body made of textile material with metal and leather inserts (Figures 7 and 8) [47,48]. For the cylindrical-conical body behind the head, there was an analogy with a wind sleeve used in aviation.

Since there were no artifacts in museums, a representative model was chosen-the statue of Brad, Romania (Figure 9). The statue was photographed with a Canon EOS DSLR camera. A total of 36 photos were taken of the entire circumference. Based on these photos, a geometric model was created, containing over 750,000 vertices and 994,000 faces in 3D space, in a file with the extension .ply (Figure 10). This method can apply to all artifacts that are touch sensitive and cannot be measured by direct methods with direct contact instruments. 


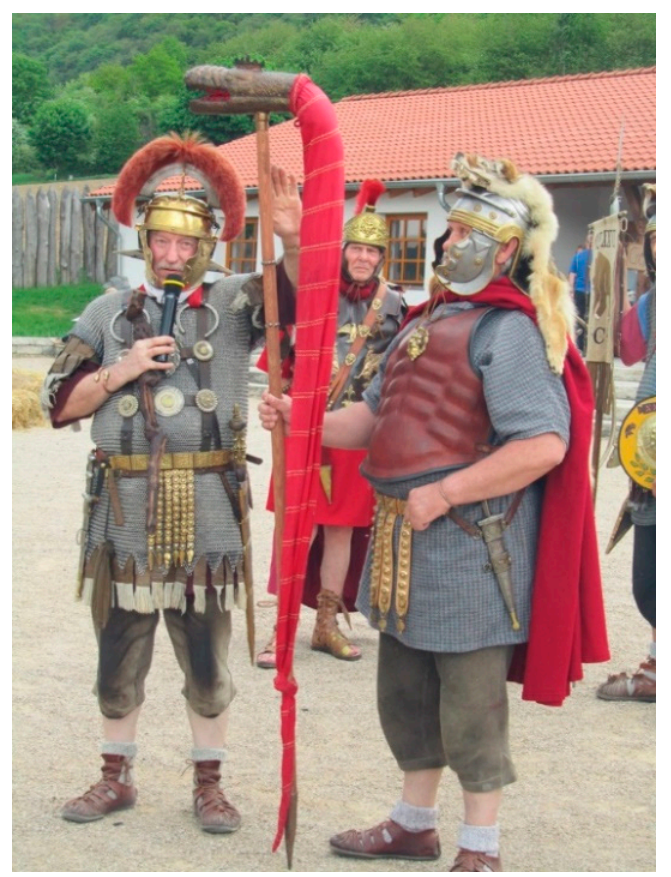

Figure 7. The Niederbieber flag carried by the Roman centurion [47].

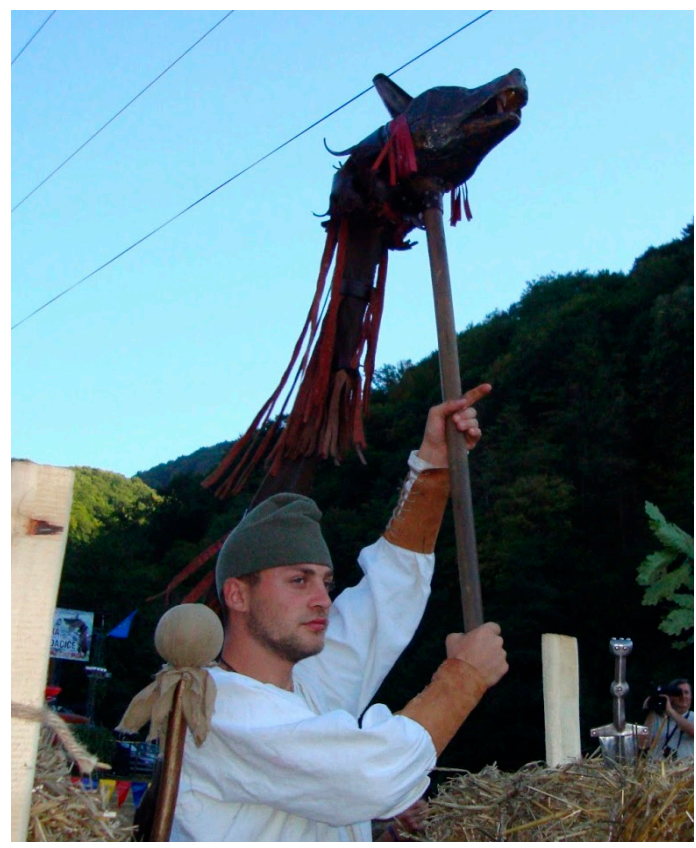

Figure 8. Dacian flag carried by one Dacian soldier-reconstitution [48].

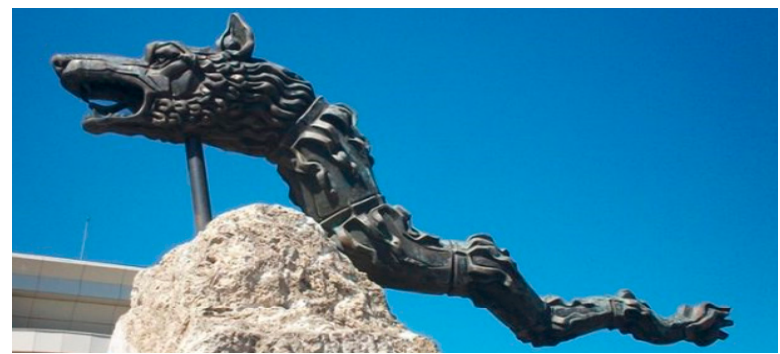

Figure 9. Dacian Dracon statue of Brad. 


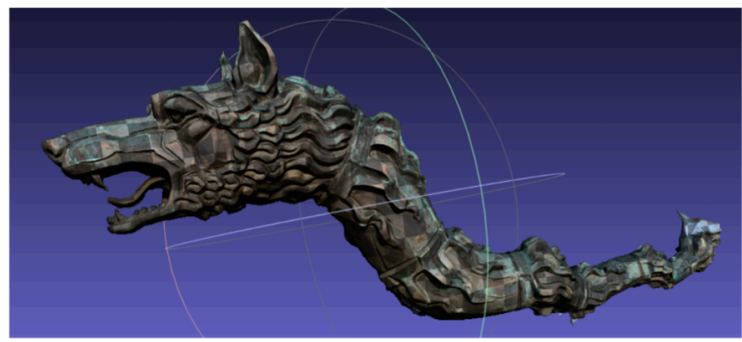

Figure 10. Reconstructed geometric model in MeshLab software (http://www.meshlab.net/).

Flag dimensions were measured using ImageJ software (https://imagej.net/) using the images on Trajan's Column bas reliefs. This software has the ability to set dimensions whose values we know and become benchmarks for measuring objects whose dimensions we do not know. On the other hand, we have made an analogy with the German dragon, whose head is about $20 \mathrm{~cm}$. The tail will be about 2.5-3 times larger than the head.

\subsection{Step Four-Identification of the Functionality of the Artifact and the Characteristics to be Analyzed}

\subsubsection{Human Perception of Sound}

According to Reference [49], we can say that in physics, sound is a vibration that typically propagates as an audible wave of pressure, through a transmission medium such as a gas, liquid, or solid. In psychology, sound is the reception of such waves and their perception by the brain. Human beings can perceive sound waves with frequencies between about $20 \mathrm{~Hz}$ and $20 \mathrm{kHz}$.

Sound waves are created by the vibration of some object or even air itself. A back-and-forth motion of an object can create them, by having air pass over a vibrating object, or by moving air, causing the vibrations. We can distinguish several ways of producing sound: (1) Vibration creates sound waves; (2) passing by vibrating object; (3) air causes its own vibration [50].

In the study that we propose to complete, one thing is very important: The level of sound intensity and the human perception of it. Thus, in Reference [51], a scale of sound intensity was identified, presented in the table below (Table 1). Here, we can identify two thresholds that we need to consider in the study we will be doing: $85 \mathrm{~dB}$ (this is roughly where long-term exposure can lead to damage) and $115 \mathrm{~dB}$ (human body begins to perceive vibration in low frequencies).

Table 1. Sound levels.

\begin{tabular}{ccc}
\hline Feeling & Sound/Noise Intensity & Description \\
\hline \multirow{3}{*}{ Comfortable } & $0-10 \mathrm{~dB}$ & Threshold of hearing \\
& $10-20 \mathrm{~dB}$ & Faintest sounds we can hear \\
& $20-30 \mathrm{~dB}$ & Leaves rusting \\
Quiet office
\end{tabular}




\subsubsection{About the Position of the Tail}

Below are some technical considerations about the position of the flag. In this idea, devices used especially at airports for viewing the wind intensity by pilots and ground staff were discussed. These devices, called the wind sleeve, act as anemometer (wind speed measuring device), but also by wind direction by turning around a vertical axis.

A windsock is a particular anemometer used for measuring wind. It consists of a cone of flexible material, air-resistance, and is tied with a larger opening of a supporting post. By blowing in the sock, the wind changes its position and its length, indicating direction and intensity. The windsock is used in places where the visual indication of force and wind direction is important, particularly in airports, petrochemical complexes, or near streets in strong wind areas [52]. In practice, polyamide PA 6.6 is used as a material, because it is lightweight but rigid and extremely durable, coated on both surfaces with a polyurethane layer (PU). Figure 11 shows a diagram of wind speeds and the standard windsock seating, according to the Federal Aviation Administration (FAA) of the United States [53]. These graphical representations show us the documented and verified ratio of the air velocity and the position of a conic cylindrical structure made of textile materials.

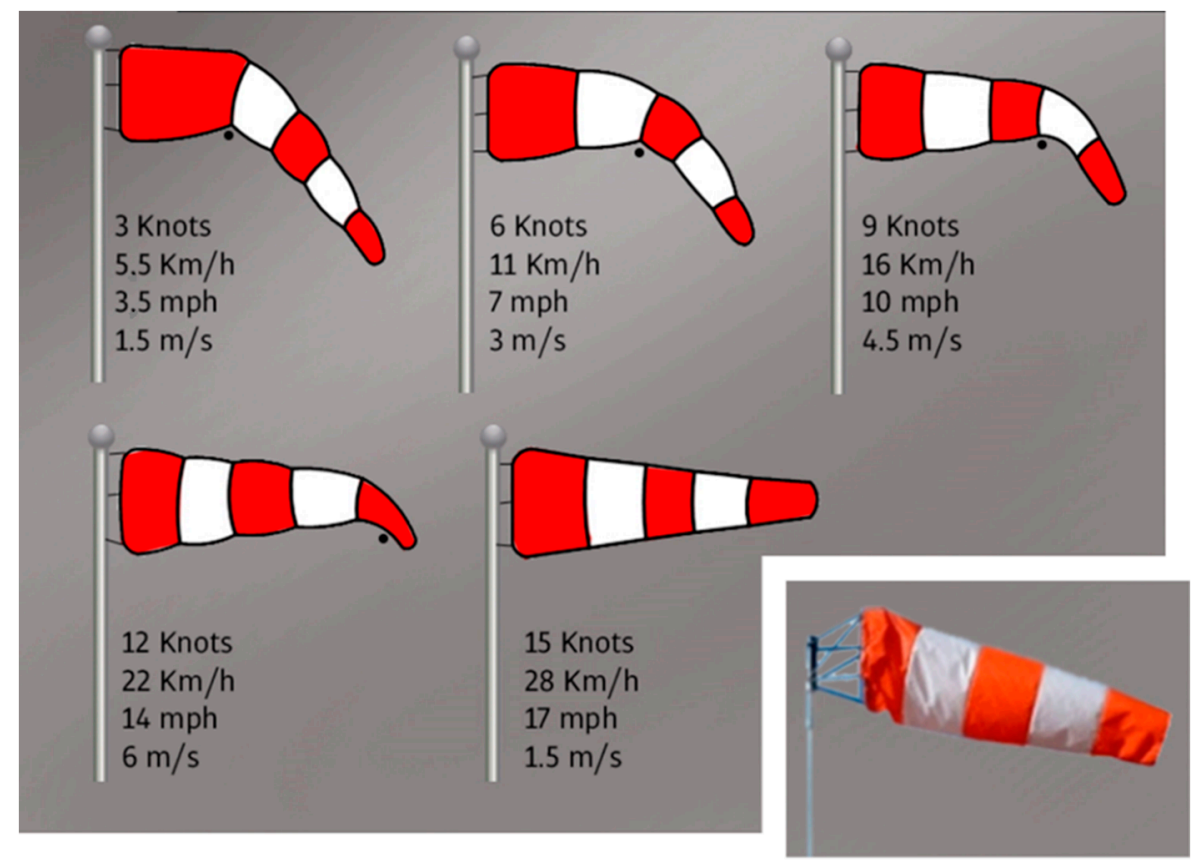

Figure 11. Windsocks are mainly used for measuring wind speed and velocity [54].

According to the running speed of a horse, which is about $40-48 \mathrm{~km} / \mathrm{h}$, we can say that the tail of the Dacian flag will become horizontal. Instead, when pedestrians wear the flag at a top speed of $12 \mathrm{~km} / \mathrm{h}$, without a frontal wind, there is little chance that the flag will settle horizontally, hence the difference of representation between the Dacian flag, which is always vertical, and the German one, which is always horizontal.

\subsubsection{Theories of Noise Production}

Analyzing the form and functionality of the Dacian flag, the following assumptions can be made [55]:

- Assumptions that take into account the functionality of the device (the noise emitted is strong enough and can propagate at a reasonable distance, can operate at a horse running speed or even lower); 
- Assumptions that take into account the fabrication of the device (manufactured with existing technologies at that time, consistent with the historical evidence we already know, easy to handle, not too hard).

Taking into account these hypotheses, there have been various theories about producing sound/noise by this type of flag [55]: The resonating head, the tail, the aeolian harp, the rotating vanes, the resonating columns, the reeds, and the whistles or flutes. Some of these hypotheses have been analyzed and excluded for various reasons that violated previously established assumptions (very large dimensions or low-intensity sounds).

One of the theories proposes the idea of producing the noise by passing air under pressure through some existing channels in the wolf's head. This technique was studied by a group of Italian researchers on an ancient rebuilt vestige-flutes. The results are presented in Reference [38] but do not confirm the production of high-intensity sounds.

Another theory assumes that the noise is not produced by the head of the flag, but by the tail. It is supposed that the tail was made of leather and canvas strips, on which were hung various metallic pieces that, on collision, made strong sounds. This theory has been studied in recent years and some results have been obtained that do not confirm the possibility of producing very strong noises. Thus, in Reference [56], there are several devices that produce sounds/noises through air movement. However, these devices operate at wind speeds above $30 \mathrm{~km} / \mathrm{h}$.

This section may be divided by subheadings. It should provide a concise and precise description of the experimental results, their interpretation, as well as the experimental conclusions that can be drawn.

\subsection{Step Five-Creating the Model for Analysis}

One of the theories we want to study here is the production of noise through the friction phenomenon between the air and the whole body of the flag, taking into account its outer geometric shape. Our assumption is that the noises are produced due to the pressure difference between the entrance and exit surfaces, the geometry, and irregular air speed of the Dacian flag.

In this paper, the finite element method (FEM) is used to determine the possible sounds/noises that could be generated. This numerical method involves more steps, of which the most important are the following: (1) Creation of the geometric model; (2) introduction of material characteristics; (3) introducing constraints and forces; (4) solving the model; (5) interpreting the results.

A virtual model of a simplified wolf's head and body was developed using CATIA software version V5R21 (Dassault Systemes, Vélizy-Villacoublay, France) and then was saved in the IGS universal format. The geometric model was then imported into ANSYS software version R16.1 (ANSYS, Inc., Southpointe, Canonsburg, PA 15317, USA) application and placed in a cylindrical shape container that would simulate the external environment. ANSYS Fluent module was used for the acoustical analysis as it allows selecting and changing various characteristics such as temperature, pressure, and air speed.

Determinations were made based on the finite element method using the dedicated ANSYS software package. We aimed to determine the value of the sound intensity emitted by the analyzed structure, measured in dB. The methodology is presented in Figure 12. For this, we used the geometric model rebuilt in the solid variant, the surface model, or dots model $\left(^{*}\right.$.ply-Polygon File Format or Stanford Triangle Format or *.stl—stereolytography file or Standard Triangle Language file) not working in this type of software. 


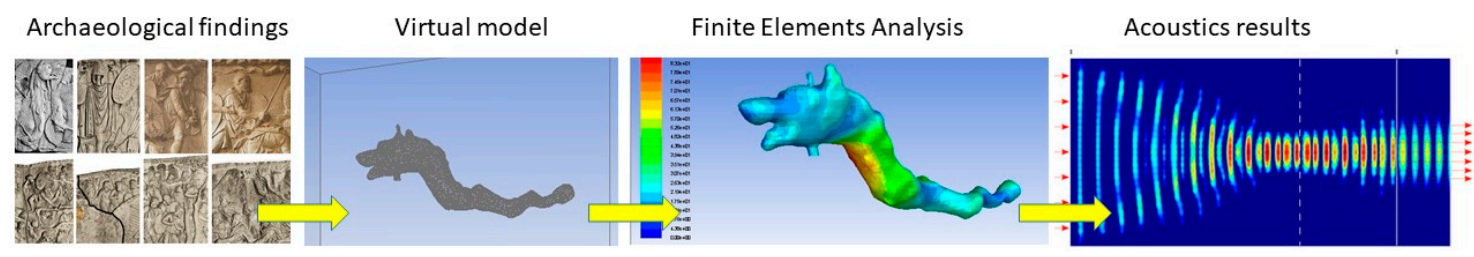

Figure 12. Methodology for reconstructing the sound of the Dacian Dracon.

For this reason, the pattern obtained after shooting and transforming in point clouds (.ply file) was processed with the FreeCAD software (http://www.freecad.com) and then saved as a STEP physical file. The solid model was discretized and then analyzed in the CFD Fluent module of ANSYS. The analysis model consists of introducing the meshed geometric model into a parallelepiped space (Figure 13), in which the fluid moves at a certain velocity, with opposite sides of the parallelepiped as input and output.

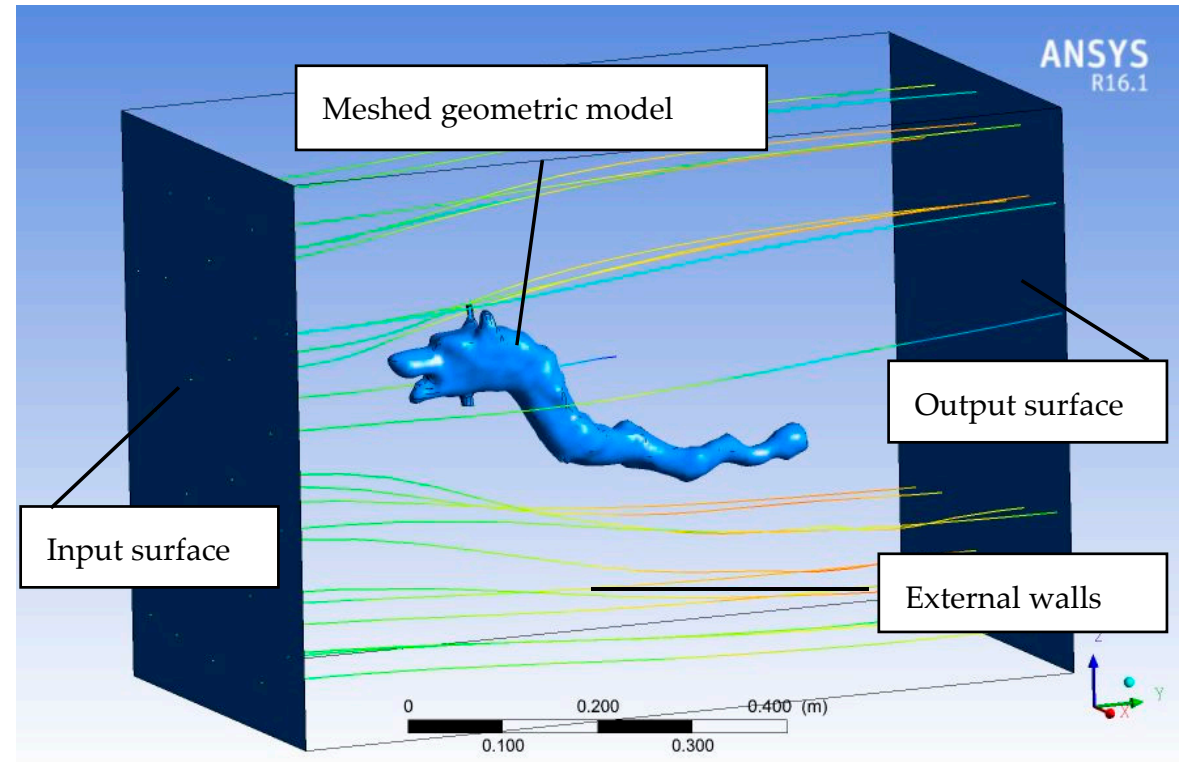

Figure 13. The Finite Element Analysis Model.

\subsection{Step Six-Running the Digital Model and Extracting Data}

Further, the analysis was performed with the ANSYS FLUENT module, which is based on Ffowcs-Williams and Hawkings (FW-H) formulation. This method adopts a time-domain integral formulation wherein time histories of acoustic signals at prescribed receiver locations are directly computed by evaluating a few surface integrals.

Usually, in many practical applications involving turbulent flows, noise does not have any distinct tones. Here, the energy of sound is distributed over a broad range of frequencies. The mathematic procedure consists of two steps: (1) A time-accurate flow solution is generated, from which time histories of the relevant variables (e.g., pressure, velocity, and density) on the selected source surfaces are obtained, and (2) sound pressure signals at the user-specified receiver locations are computed using the source data collected during the first step [57].

The physical properties of the fluid from the analysis volume, the air velocity, along with the analytical model, can be modified in a very wide range. Moreover, the analysis program has the possibility to visualize fluid flow alongside the analyzed solid model (Figure 14) and the intensity of the noise generated by airflow (Figure 15). 


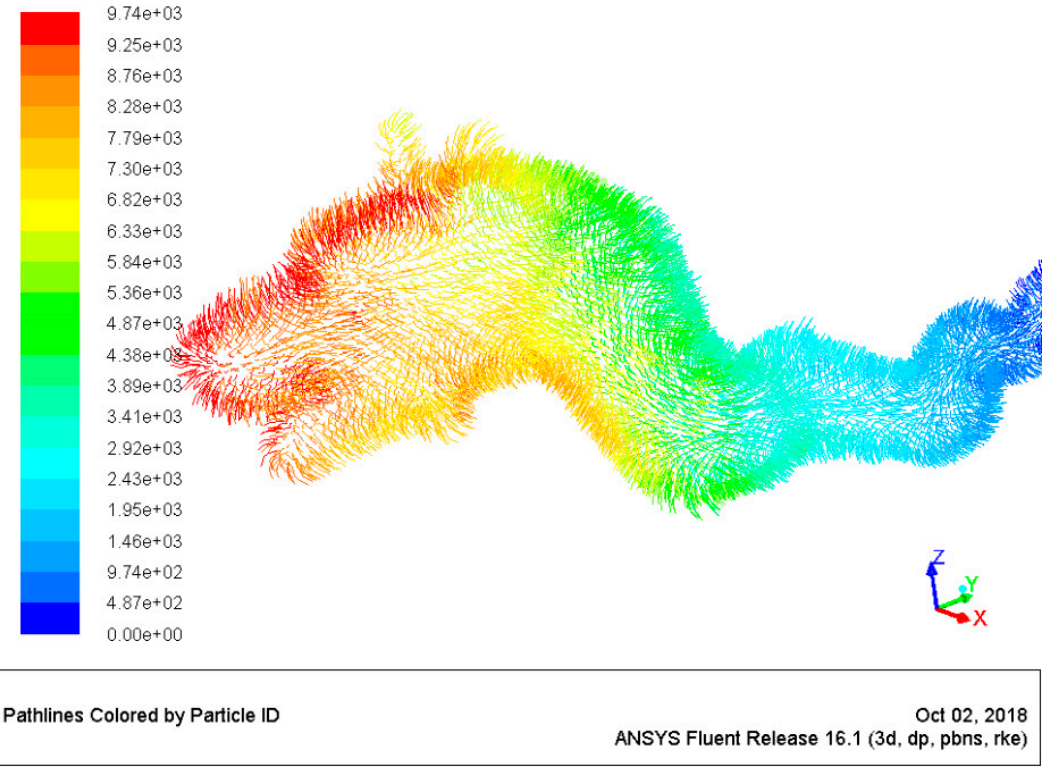

Figure 14. The fluid flow alongside the analyzed solid model (particles-based model).

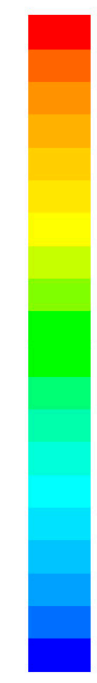

$1.09 \mathrm{e}+02$
$1.03 \mathrm{e}+02$
$9.79 \mathrm{e}+01$
$9.25 \mathrm{e}+01$
$8.71 \mathrm{e}+01$
$8.16 \mathrm{e}+01$
$7.62 \mathrm{e}+01$
$7.07 \mathrm{e}+01$
$6.53 \mathrm{e}+01$
$5.98 \mathrm{e}+01$
$5.44 \mathrm{e}+01$
$4.90 \mathrm{e}+01$
$4.35 \mathrm{e}+01$
$3.81 \mathrm{e}+01$
$3.26 \mathrm{e}+01$
$2.72 \mathrm{e}+01$
$2.18 \mathrm{e}+01$
$1.63 \mathrm{e}+01$
$1.09 \mathrm{e}+01$
$5.44 \mathrm{e}+00$
$0.00 \mathrm{e}+00$

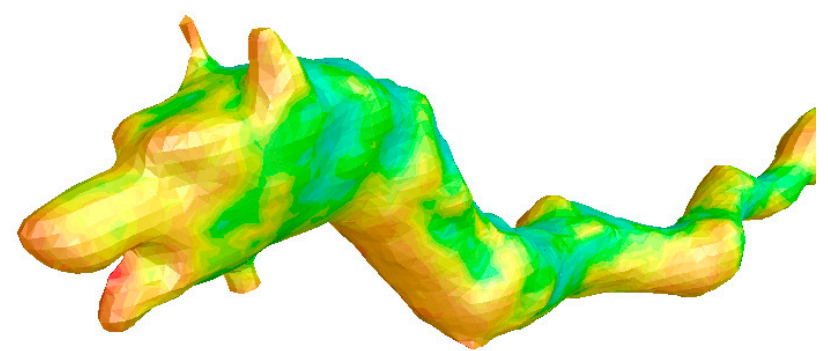

Contours of Acoustic Power Level (dB)

Oct 02,2018

ANSYS Fluent Release 16.1 (3d, dp, pbns, rke)

Figure 15. Intensity of the generated noise (dB).

Considering this type of analysis model, it was found that the noise emitted during the movement of the body through a fluid medium with the air consistency did not have a very high intensity value; that is, it does not enter the noise discomfort level according to the intensity values scale.

\subsection{Results from FEM Analysis}

Through this analysis, we aimed to determine the noise intensity values, and not focus on other sound characteristic (harmonics, timbre, etc.). The simplified virtual model generated around 35-70 dB, except for the ears, which exceeded values of $100 \mathrm{~dB}$.

Figure 16 shows an FEM analysis which certifies that the elevations of a solid body which is moving in the air flow causes high levels of noise. In our case, it is the wolf's ears. According to the analysis performed on this simple model, it is found that the areas with aggressive geometry determine values about 10 times higher than those with aerodynamic geometry. 


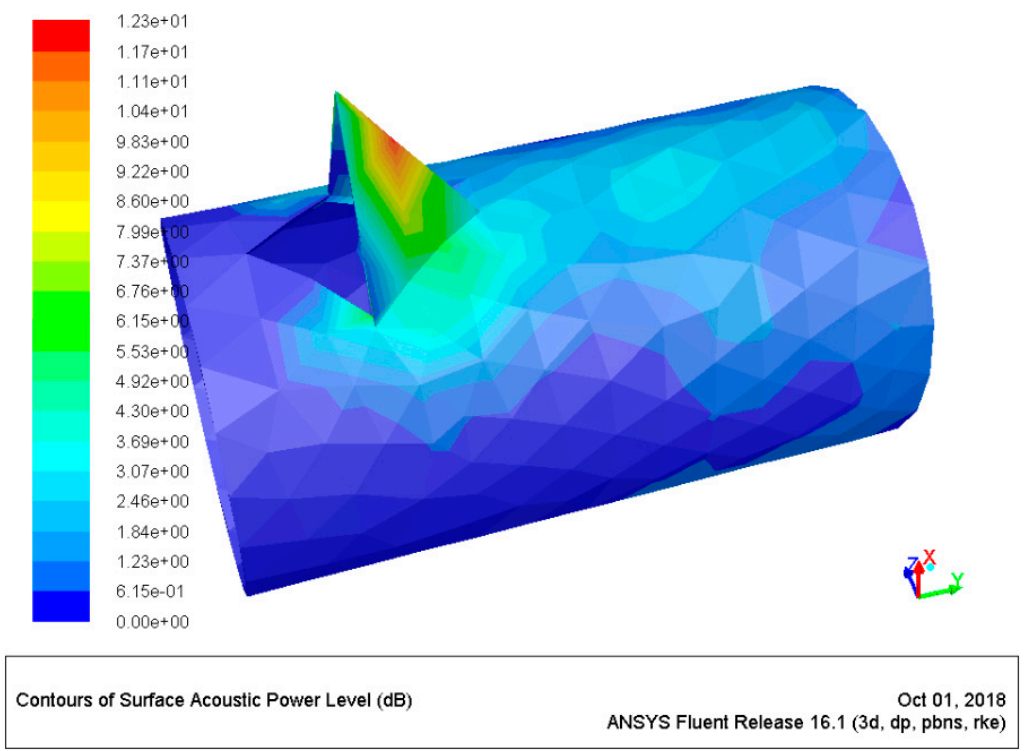

Figure 16. Airflow analysis over aggressive geometries.

Preliminary results partially confirm the historical sources. However, in order to draw a solid conclusion regarding the effects of the sound/noise produced by the Dacian Dracon, a more complex analysis is required that aims to identify timbre and harmonics.

The reconstructed sounds may then be integrated in immersive environments to make the imaginary world more realistic and enhance the feeling of being in another century.

\subsection{Creating a Prototype Presentation Stand}

\subsubsection{Description of the Stand-Measuring the Intensity of the Sound on the Prototype}

The stand is structured on two distinct areas: The upper part contains a functional Dacian Dracon model at 1:4 scale and the lower part, where a personal computer with a touchscreen able to running applications and short descriptive films on the history and functioning of the Dacian flag is installed (Figure 17).

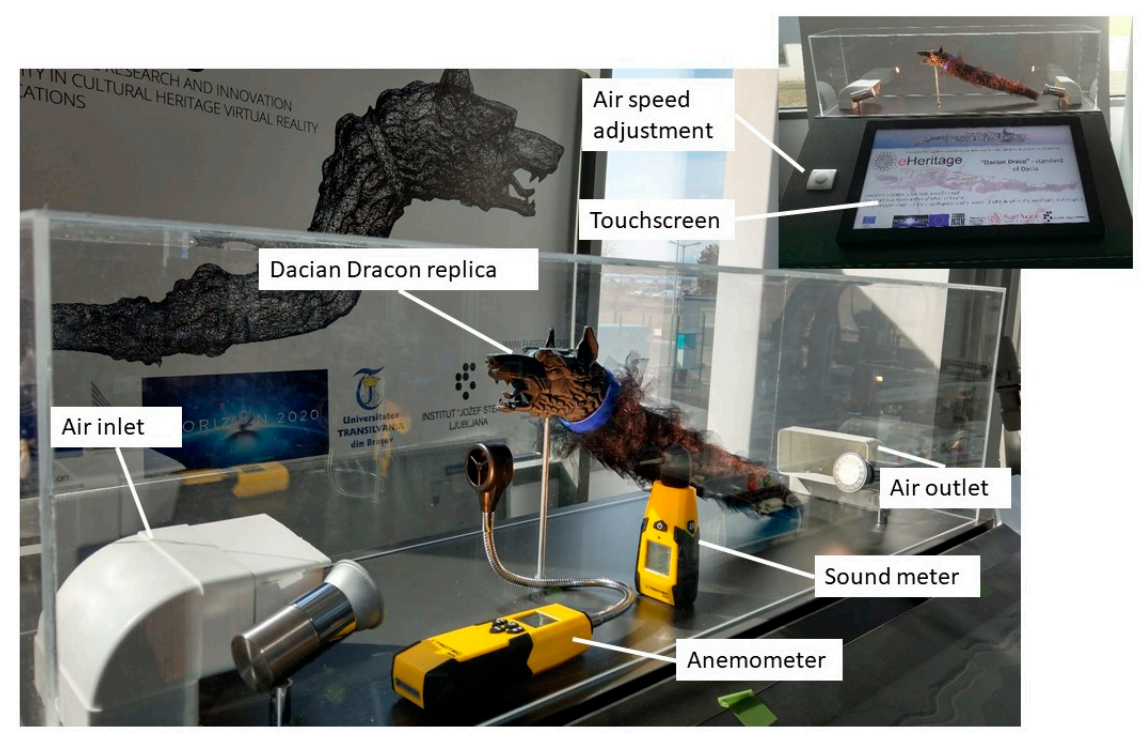

Figure 17. Demonstration stand for the museum. 
In order to gain a practical determination of the sound intensity of the Dacian Dracon flag, we used a system consisting of a model of the Dacian flag, an air system capable of generating variable air velocity, an air velocity measurement anemometer, and a sound meter device for recording the sound intensity (see Figure 17).

\subsubsection{Results from Stand Analysis}

The air flow rate can be changed between 0 and $10 \mathrm{~m} / \mathrm{s}$. Various airflows have been generated and the intensity of the noise has been measured. With the recorded values, a graph was plotted (sound/noise intensity- $\mathrm{dB}$ vs. air flow speed). The values were interpreted. Airborne noise emission levels are very low, confirming the values obtained using the finite element analysis. It can be firmly stated that this is not the principle of producing noise.

On the other hand, in order to confirm the above results, we can study some research reports on the determination of the noise produced by friction between moving cars and the air. These studies show that maximum noise in air friction is produced by body protuberances, i.e., mirrors, elerons, spoilers. The noise values produced by them are relatively smaller $(50-90 \mathrm{~dB})$ than the values which we are tracking [58].

\section{Discussion and Conclusions}

In the first part of the paper, the author presented a study based on the AHP method, which was conducted in order to identify the most important elements that may interest the public regarding intangible cultural heritage. In this respect, the author has identified in the scientific papers in this area of research the use of 3D virtual reconstruction technologies of buildings and tried to extend this area to other research domains based on new technologies in engineering. Thus, according to the AHP study, other fields of interest have been identified and classified, besides the classic ones of 3D reconstruction: Functioning of the artifacts, languages, clothes, visual sensation of material, knowledge, sounds, dance choreography, tells, and legends. For this work, we considered that functioning of the artifact represents the point of maximum interest.

The author found that there is information about some historical elements that do not seem to be verisimilar and cannot be verified by traditional classical methods. Thus, to verify this information in a controlled way, in order to confirm or refute it, the author proposed, detailed, and exemplified an algorithm for the analysis of historical vestiges from the intangible range. This approach involves several types of analysis, from historical/archaeological studies to specialized engineering taken from other engineering fields: Reconstruction and 3D modelling, and analysis using MBS and FEM methods.

In the second part of the paper, we presented some techniques of virtual reconstruction and analysis, which were used for studying certain elements: Bows with arrows, hand saws, bas reliefs, printing machines, and underfloor heating systems.

In the third part of the paper, we presented a case study in which the element analyzed was the Dacian flag (Dracon). The problem in this example was the verification of the noise produced by this object, with information from some historical sources. For this purpose, the algorithm proposed in the first part of the paper was implemented and large parts of the known noise generation methods were analyzed methodically.

As a conclusion of this study, based on the engineering analyses performed, at least in terms of the noise generation methods taken into account, we can say that the Dacian Dracon flag was used by the Dacian army especially for the purpose of representativeness and symbolism, being a sign representing the location of an army segment/group on the battlefield.

Based on the engineering methods used in this study, it was concluded that the sounds produced by airborne rubbing are not very strong, and they cannot be identified in the sound of a battle. On the other hand, the subject remains open, and there are other methods of producing noise that have not been verified (e.g., the flute principle). 
In conclusion, this work makes a connection between the intangible historical vestiges and the modern methods of analysis used in engineering, with the purpose of clarifying some aspects regarding the shape, structure, functioning, and technical characteristics of elements used in the past, for which we do not have enough information.

The described procedure has certain limitations. Therefore, it cannot be said that the analysis made in the case study is exhaustive. Above are some research directions that have not been addressed. That is why, due to the technological advance that we participate in day by day, we will surely discover new research directions that can supplement and add value to the procedure described in this paper.

New research can be done to study the materials from which various artifacts, tools, and devices used in everyday life were built, the way of extracting and preparing various metallic or other materials, and the technologies of manufacturing various tools. These results can be viewed using virtual reality technologies already on the market or through new $3 \mathrm{D}$ viewing technologies that are now in the research stage.

Funding: This research was funded by European Commission, grant number 692103, H2020-TWINN-2015, project eHeritage-Expanding the Research and Innovation Capacity in Cultural Heritage Virtual Reality Applications.

Conflicts of Interest: The author declares no conflict of interest. The funders had no role in the design of the study; in the collection, analyses, or interpretation of data; in the writing of the manuscript, or in the decision to publish the results.

\section{References}

1. Definition of Heritage. Available online: https://www.collinsdictionary.com/dictionary/english/heritage (accessed on 13 February 2019).

2. UNESCO. Tangible Cultural Heritage. Available online: http://www.unesco.org/new/en/cairo/culture/ tangible-cultural-heritage/ (accessed on 4 April 2019).

3. UNESCO. Text of the Convention for the Safeguarding of the Intangible Cultural Heritage. Available online: https://ich.unesco.org/en/convention (accessed on 4 April 2019).

4. Isa, W.M.W.; Zin, N.A.M.; Rosdi, F.; Sarim, H.M. Digital Preservation of Intangible Cultural Heritage. Indones. J. Electr. Eng. Comput. Sci. 2018, 12, 1373-1379. [CrossRef]

5. Lin, Q.; Lian, Z. On Protection of Intangible Cultural Heritage in China from the Intellectual Property Rights Perspective. Sustainability 2018, 10, 4369. [CrossRef]

6. Suárez, R.; Alonso, A.; Sendra, J.J. Archaeoacoustics of intangible cultural heritage: The sound of the Maior Ecclesia of Cluny. J. Cult. Herit. 2016, 19, 567-572. [CrossRef]

7. European Communities. DigiCULT, Technological Landscapes for Tomorrow's Cultural Economy, Unlocking the Value of Cultural Heritage: Full Report; Part of Library of Congress Online Catalog (978,398); Luxembourg, 2002. Available online: https://www.loc.gov/item/2005373383/ (accessed on 23 March 2019).

8. Bruno, F.; Bruno, S.; De Sensi, G.; Luchi, M.-L.; Mancuso, S.; Muzzupappa, M. From 3D reconstruction to virtual reality: A complete methodology for digital archaeological exhibition. J. Cult. Herit. 2010, 11, 42-49. [CrossRef]

9. Del Barrio, M.J.; Devesa, M.; Herrero, L.C.; Prieto, L.C.H. Evaluating intangible cultural heritage: The case of cultural festivals. City Cult. Soc. 2012, 3, 235-244. [CrossRef]

10. Antonya, C.; Butnariu, S.; Gams, M. Haptic Interface Design for Experiencing Ancient Works. In Proceedings of the 19th International Multiconference on Information Society-IS 2016, Ljubljiana, Slovenia, 10-14 October 2016; pp. 16-19.

11. Butnariu, S.; Duguleană, M.; Brondi, R.; Gîrbacia, F.; Postelnicu, C.C.; Carrozzino, M. An interactive haptic system for experiencing traditional archery. Acta Polytech. Hung. 2018, 15, 185-208. [CrossRef]

12. Birliba, D.M. Sfintenia Cuvintelor Tiparite. Available online: http://ziarullumina.ro/sfintenia-cuvintelortiparite-114417.html (accessed on 10 November 2018).

13. Butnariu, S.; Gîrbacia, F. High Quality 3D Restoration of Photographed Structures Using V.R. Technologies. Appl. Mech. Mater. 2014, 464, 391-398. [CrossRef]

14. Butnariu, S.; Gîrbacia, F.; Orman, A. Methodology for 3D reconstruction of objects for teaching virtual restoration. Int. J. Comput. Sci. Res. Appl. 2013, 3, 16-21. 
15. Girbacia, F.; Butnariu, S.; Orman, A.; Postelnicu, C.C. Virtual restoration of deteriorated religious heritage objects using augmented reality technologies. Eur. J. Sci. Theol. 2013, 9, 223-231.

16. Delatte, N. Lessons from Roman Cement and Concrete. J. Prof. Issues Eng. Educ. Pract. 2001, 127. [CrossRef]

17. Brune, P.; Perucchio, R.; Ingraffea, A.R.; Jackson, M.D. The toughness of imperial roman concrete. In Proceedings of the 7th International Conference on Fracture Mechanics of Concrete and Concrete Structures, Jeju Island, Korea, 23-28 May 2010.

18. Lo Dico, G.; Semilia, F.; Milioto, S.; Parisi, F.; Cavallaro, G.; Inguì, G.; Lazzara, G. Microemulsion Encapsulated into Halloysite Nanotubes and their Applications for Cleaning of a Marble Surface. Appl. Sci. 2018, 8, 1455. [CrossRef]

19. Abbate, M.; D'Orazio, L. Water Diffusion through a Titanium Dioxide/Poly(Carbonate Urethane) Nanocomposite for Protecting Cultural Heritage: Interactions and Viscoelastic Behavior. Nanomaterials 2017, 7, 271. [CrossRef]

20. Cavallaro, G.; Milioto, S.; Parisi, F.; Lazzara, G. Halloysite Nanotubes Loaded with Calcium Hydroxide: Alkaline Fillers for the Deacidification of Waterlogged Archeological Woods. ACS Appl. Mater. Interfaces 2018, 10, 27355-27364. [CrossRef]

21. Zhao, G.; Zan, H.; Di, B.; Zhu, W.; Yu, Y. Research on Virtual Reconstruction Technology of Tujia Brocade Handcrafts. 3D Res. 2018, 9, 54. [CrossRef]

22. Lang, Y.; Deng, X.; Zhang, K.; Wang, Y. Construction of Intangible Cultural Heritage Spot Based on AR Technology-Taking the Intangible Cultural Heritage of the Li Nationality in the Areca Valley as an Example. IOP Conf. Ser. Earth Environ. Sci. 2019, 234, 012119. [CrossRef]

23. Zhang, Y.; Han, M.; Chen, W. The strategy of digital scenic area planning from the perspective of intangible cultural heritage protection. EURASIP J. Image Video Process. 2018. [CrossRef]

24. Hajdin, M.; Kico, I.; Dolezal, M.; Chmelik, J.; Doulamis, A.; Liarokapis, F. Digitization and Visualization of Movements of Slovak Folk Dances. In The Challenges of the Digital Transformation in Education; ICL 2018, Advances in Intelligent Systems and Computing; Auer, M., Tsiatsos, T., Eds.; Springer: Cham, Switzerland, 2019; Volume 917.

25. Vitorillo, J.; Arriola, M.S.M. Safeguarding intangible cultural heritage in the Philippines. In Routledge Handbook of Cultural and Creative Industries in Asia; Lim, L., Lee, H.-K., Eds.; Routledge: London, UK, 2018; pp. 372-382. [CrossRef]

26. Furukawa, K.; Kojima, K.; Hachimura, K. Digital Renovation and Archives of Japanese Ancient Ritual Performance at the World Cultural Heritage; Niutsuhime Shrine. In Advances in Intelligent Systems and Computing, Proceedings of the 18th International Conference on Geometry and Graphics-ICGG 2018, Milan, Italy, 3-7 August 2018; Cocchiarella, L., Ed.; Springer: Cham, Switzerland, 2019; Volume 809.

27. Dagnino, F.M.; Hadjileontiadis, L.J.; Ott, M.; Pozzi, F. An Integrated Platform Supporting Intangible Cultural Heritage Learning and Transmission: Definition of Requirements and Evaluation Criteria. J. Comput. Inf. Technol. 2014, 22, 277-292. [CrossRef]

28. Dimitropoulos, K.; Tsalakanidou, F.; Nikolopoulos, S.; Kompatsiaris, I.; Grammalidis, N.; Manitsaris, S.; Denby, B.; Crevier-Buchman, L.; Dupont, S.; Charisis, V.; et al. A Multimodal Approach for the Safeguarding and Transmission of Intangible Cultural Heritage: The Case of i-Treasures. IEEE Intell. Syst. 2018, 33, 3-16. [CrossRef]

29. Mortara, M.; Catalano, C.E.; Bellotti, F.; Fiucci, G.; Houry-Panchetti, M.; Petridis, P. Learning cultural heritage by serious games. J. Cult. Herit. 2014, 15, 318-325. [CrossRef]

30. Yang, Y.; Zhang, D.; Ji, T.; Li, L.; He, Y. Designing Educational Games Based on Intangible Cultural Heritage for Rural Children: A Case Study on "Logic Huayao". In AHFE 2018: Advances in Human Factors in Wearable Technologies and Game Design; Advances in Intelligent Systems and Computing; Ahram, T., Ed.; Springer: Cham, Switzerland, 2019; Volume 795.

31. Scarre, C.; Lawson, G. Archaeoacoustics. McDonald Institute Monographs; McDonald Institute for Archaeological Research: Cambridge, UK, 2006.

32. Till, R. Songs of the stones: The acoustics of Stonehenge. In The Sounds of Stonehenge; Banfield, S., Ed.; Archaeopress: Oxford, UK, 2009; pp. 17-39.

33. The European Acoustic Heritage Project. Available online: http://europeanacousticheritage.eu/the-project/ (accessed on 4 March 2017). 
34. Avanzini, F.; Canazza, S.; de Poli, G.; Fantozzi, C.; Pretto, N.; Rodà, A.; Angelini, I.; Bettineschi, C.; Deotto, G.; Faresin, E.; et al. Archaeology and virtual acoustics. A pan flute from ancient Egypt. In Proceedings of the 12th International Conference on Sound and Music Computing (SMC-15), Maynooth, Ireland, 30 July-1 August 2015.

35. Avanzo, S.; Barbera, R.; De Mattia, F.; La Rocca, G.; Sorrentino, M.; Vicinanza, D. Data sonification of volcano seismograms and Sound/Timbre reconstruction of ancient musical instruments with Grid infrastructures. Procedia Comput. Sci. 2010, 1, 397-406. [CrossRef]

36. Sulaksna, K.; Thamatkeng, P. Heat Transfer \& Fluid Flow Simulation with ANSYS (Tutorial); School of Mechanical Engineering, Suranaree University of Technology. Available online: http://eng.sut.ac.th/me/2014/document/ training/CAETraining(Fluid).pdf (accessed on 20 January 2019).

37. Roman Central Heating. Available online: https://www.romanobritain.org/12_innovations/inv_central_ heating.php\#.UqdIktJdVME (accessed on 20 January 2019).

38. Draco. Available online: https://ro.wikipedia.org/wiki/Draco (accessed on 5 December 2017).

39. Columna lui Traian, Roma. Available online: http://www.columnaluitraian.ro/ro/ (accessed on 25 November 2017).

40. Trajan's Column. Available online: https://www.nationalgeographic.com/trajan-column/ (accessed on 25 November 2017).

41. Wheeler, E.L. The Occasion of Arrian's Tactica; Duke University: Durham, NC, USA, 1978.

42. Iliescu, V.; Popescu, V.C.; Stefan, G. (Eds.) Izvoare Privind Istoria Romaniei, Partea I; Academiei Romane: Bucharest, Romania, 1964.

43. Dacian Draco-Dragonul Dacic. Available online: http://romaniamegalitica.blogspot.ro/2011/12/daciandraco-dragonul-dacic.html (accessed on 4 February 2018).

44. The Dacians. Available online: http://www.angelfire.com/realm/vlachs/ (accessed on 4 February 2018).

45. Die Drachenstandarte von Niederbieber. Available online: http://www.deichstadtweg.de/kelten_und_ roemer_in_neuwied_4.htm (accessed on 25 November 2017).

46. Carnyx. Available online: https://en.wikipedia.org/wiki/Carnyx (accessed on 11 April 2018).

47. Römische Soldaten in Ihrer "Freizeit". Available online: http://augustusforum.de/forum/limesfest_in_ rheinbrohl_11_und_12_mai_2013_teil_ii-6488803-t.html (accessed on 23 March 2019).

48. Civilizatia Dacica-Festivalul Dacic Dac Fest Costesti. Available online: http://tudorphotoblog.blogspot.ro/ 2013/03/civilizatia-dacica-festivalul-dacic.html (accessed on 23 March 2019).

49. Sound. Available online: https://en.wikipedia.org/wiki/Sound (accessed on 11 April 2018).

50. Kurtus, R. Creating Sound Waves. Available online: http://www.school-for-champions.com/science/sound creation.htm (accessed on 5 December 2017).

51. Everything You Should Know about Sound. Available online: https://waitbutwhy.com/2016/03/sound.html (accessed on 5 December 2017).

52. Windsock. Available online: http://kite-shop.ro/windsock (accessed on 26 November 2017).

53. Windsock. Available online: https://en.wikipedia.org/wiki/Windsock (accessed on 26 November 2017).

54. American Inventor, 7 March 2016. Available online: https://patentyogi.com/american-inventor/did-youknow-that-the-white-and-orange-strips-on-windsocks-are-not-for-decoration-they-actually-indicaterelative-wind-speeds/ (accessed on 26 November 2017).

55. Taylor, P. How to Make a Draco (3)—The Noise. Available online: http://www.fectio.org.uk/articles/ makedraco3.htm (accessed on 11 April 2018).

56. Kite Musical Instruments \& Aeolian Musical Instruments. Available online: http://www.windmusik.com/ html/soundex.htm (accessed on 25 November 2017).

57. Ffowcs-Williams, J.E.; Hawkings, D.L. Sound Generation by Turbulence and Surfaces in Arbitrary Motion. Proc. R. Soc. Lond. 1969, A264, 321-342.

58. Chu, Y.-J.; Shin, Y.-S.; Lee, S.-Y. Aerodynamic Analysis and Noise-Reducing Design of an Outside Rear View Mirror. Appl. Sci. 2018, 8, 519. [CrossRef]

(C) 2019 by the author. Licensee MDPI, Basel, Switzerland. This article is an open access article distributed under the terms and conditions of the Creative Commons Attribution (CC BY) license (http://creativecommons.org/licenses/by/4.0/). 